\title{
The impact of national political culture on the Global development of Entrepreneurial ecosystems
}

\author{
Gennady Alpatov ${ }^{1,}{ }^{*}$, Elena Korostyshevskaya ${ }^{1}$ Olga Stoianova $^{2}$, Kirill Gusarov $^{1}$, and Elena \\ Bortnikova $^{3}$ \\ 1 St. Petersburg State University, Economic Faculty, Department of Economic Theory, 7/9 \\ Universitetskaya nab., St. Petersburg, 199034, Russia. \\ 2 St. Petersburg State University, Economic Faculty, Department of Information Systems in \\ Economics, 7/9 Universitetskaya nab., St. Petersburg, 199034, Russia. \\ ${ }^{3}$ Herzen University, The Faculty of Philology, 48 Moika Embankment, St. Petersburg, 191186, \\ Russia.
}

\begin{abstract}
Research background: Numerous attempts not only in the Russian Federation but also in many other countries to copy successful examples of the entrepreneurial ecosystem (EEs) from the USA did not lead to equally outstanding results. In scientific literature and in the media, the underestimation of the influence of informal institutions, also called cultural traditions of the country and business customs, is increasingly cited as a reason for that unfulfilled expectations.

We postulate that the main reason for unfulfilled expectations lies in the underestimation of the influence of political culture.

Purpose of the article: the goal is to prove the hypothesis that the prevailing culture of statism hinders the development of effective relationships between two key EEs actors - founders and venture funds.

Methods: analysis of data from a wide range of publications by keywords and their classification into groups of factors that influence on EEs.

Findings \& Value Added:

- The mature EEs dictates the rules to every new member, but the evolving EEs itself obeys the code of conduct that existed before it appeared.

- The larger the share of state-funded startups, the stronger the distorting influence of the state in the sensitive period of EEs formation.

- As a result of the contradiction that has arisen between the cultural environment and the need for security and support for startups, there is an outflow of startups to EEs with a friendly environment. This is the main reason for the lack of private venture capital in the country.
\end{abstract}

Keywords: innovation ecosystem; venture capital; startups; informal institutions

JEL Classification: $G 24 ; M 13 ; O 31 ; O 38$

\footnotetext{
${ }^{*}$ Corresponding author: g.alpatov@spbu.ru
} 


\section{Introduction}

\subsection{Research background}

The Entrepreneurial ecosystem (EEs) is a system in which each element performs systemic functions for other elements. The general focus of EEs self-development is the implementation of the process of transforming ideas into innovations, embodied in new businesses. This Ecosystem is a space of favorable interaction, where people come with their projects and receive funding, assessment from accelerators, business angels, and investors have the opportunity to choose from a portfolio of projects and reduce risks thanks to EEs protective tools. The ecological approach of the EE framework has links to 'economic gardening' as a metaphor, when specific environments promote high growth of firms and high rates of new business startups. (Alvedalen and Boschma, 2017)

Fifty years ago, only Silicon Valley and later Tel Aviv - Jerusalem were mentioned in various sources as possible role models. (Sakari, 2021) Innovative ecosystems have become widespread in the world in recent years. The emergence of third generation mobile broadband $(3 \mathrm{G})$ allowed users to freely browse the web from their smartphones and stream or upload videos. It was a driver of the rapid expansion of social media and for the globalization of EE. (Guriev et al., 2021)

They have become a determining factor in the economic growth of countries, since they are a kind of "factories" for the production of new business and its scaling. Now, according to the annual report (Startup Genome, 2021), there are 40 successful EEs in the world For the second consecutive years Silicon Valley, New York City, London, Beijing, Boston, Tel Aviv - Jerusalem, Los Angeles remain the top seven EEs unchanged. These ecosystems are in a league of their own and have a combined value of $\$ 1.5$ trillion, 1.7 times that of the rest of the top 40 EEs. Silicon Valley maintains the status quo, ranking first since 2012. London is a magnet for talent from around the world, rising from 8th in 2012 to 2nd. In addition to them, Startup Genome also included 100 emerging EEs in its repots (Startup Genome, 2020). Their total cost is estimated at \$ 348 billion. For comparison, the cost of one Silicon Valley is $\$ 677$ billion. (Startup Genome, 2021)

It would seem that innovative ecosystems have common characteristics. The imprint of successful EEs can therefore be implemented in another country. A good example is the copying in EEs Tel Aviv - Jerusalem of the entrepreneurial ecosystem in Silicon Valley. (Avnimelech and Teubal, 2006) Startups have become the engine of economic growth and politicians are investing more in developing EEs in their countries. However, despite the global nature of startups and venture capital, their common characteristics and successful examples of imprints, the literature notes the impossibility of direct copying and there is a desire to preserve traditional national approaches to imprints from the United States. What are the implications of creating a new entrepreneurial culture remains an open question. (Alvedalen and Boschma, 2017)

\subsection{Purpose of the article}

Using the example of Russia, prove the hypothesis that the established culture of statism is a factor that is difficult to change. Its structure, the accepted customs of making government decisions, prevents the emergence of new relationships between founders of startups and venture capital funds, as two key actors in EEs. 


\section{Methods}

Analysis of data from a wide range of publications by keywords and their classification into groups of generalizing factors of the influence of political culture and informal institutions on EEs already created in Russia.

\section{Results}

Data from various sources on the emerging problems of small and medium-sized innovative businesses and the reasons for the slowdown in innovation in Russia were summarized in order to identify the reasons for the low rates of economic growth.

In Russia, the number of organizations that had R\&D departments in their composition from 2015 to 2020 decreased from 10.6 to $5 \%$ of the total number of organizations. (Gokhberg et al., 2021) The number of researchers decreased following a reduction in state budget funding from 826.7 thousand in 2013 to 758.5 in 2018 , or $8.2 \%$. (UNESCO, 2020)

As it shown in the Table 1, venture funds and funds for supporting scientific and innovative activities are small in comparison with the direct expenditures of the federal budget. They cannot influence innovation. Organizations' own funds are spent on the purchase of new equipment and construction of production facilities, and not for buying startups.

Table 1. Russia. Cost structure for innovation activities by funding sources: 2019

(percent).

\begin{tabular}{|c|c|c|c|}
\hline $\begin{array}{c}\text { Own funds of } \\
\text { organizations }\end{array}$ & $\begin{array}{c}\text { Federal } \\
\text { budget }\end{array}$ & $\begin{array}{c}\text { Funds for } \\
\text { support of } \\
\text { scientific and } \\
\text { innovation } \\
\text { activities }\end{array}$ & $\begin{array}{c}\text { Venture } \\
\text { funds and } \\
\text { private } \\
\text { equity funds }\end{array}$ \\
\hline 56.3 & 23.2 & 0.1 & 0.004 \\
\hline
\end{tabular}

Source: Gokhberg, at al., 2021.

At the same time, the structure of funding sources is unchanged, which indicates the inoperability of the state function of stimulating private investment. (Alpatov et al., 2020) But one comment should be made. In reality, an unfriendly environment does not crowd out private investments; it does not allow them to emerge. The predominance of government funding brings with it legislation that is significantly different from British law, which is guided by founders and investors in developed EEs. The Russian legal system is notable for the lack of reliable business protection.

This is confirmed by the Ease of Doing Business Rank. According to World Bank, Russia improved its position in this indicator and in 2020 was ranked 28th. However, a number of indicators characterizing support for a new business were significantly lower. Business support is part of its defense, reflecting the ability for startups to hedge risks. Starting a business was rated 40, Resolving insolvency - 57, Paying taxes - 58, Protecting minority investors -72 . (World Bank, 2021) These indicators for which Russia occupies significantly lower places.

As a result, all the variety of expert assessments points to one common reason, the predominance of state funding for innovation and, as a consequence, the influence of political culture on business culture. This influence exists in all countries, but the political culture in them is different.

In recent years, there has been a transformation in the attitude of political elites towards entrepreneurs in Russia. The "National entrepreneurship support" project was introduced; a 
number of support programs were launched at the regional level with the expectation of performance efficiency. Two IT platforms ("Business Navigator" and "My business") aimed at nascent and early staged entrepreneur's support have been successfully started. Let us consider the features of the following projects created by the state from the standpoint of the distorting influence of the etatism culture. These are 1. Projects for teenagers. 2. Centers at universities. 3. EEs Moscow - Center for the Development and Commercialization of New Technologies "Skolkovo".

1. Projects for teenagers. The Russian government is now launching a talent search program. Technoparks "Quantorium", from 10 to 18 years old, 13 technological directions, free of charge, in all regions of the country were opened at the expense of the state budget; 2021: 183 technoparks, 2024: 428 technoparks. Digital education centers "IT-hub", from 7 to 18 years old, training in IT technologies, free of charge, 2021: 126 centers, 2024: 341 centers. Educational center "Sirius" (Sochi) for gifted children from 10 to 17 years old, free accommodation and training (24 days program). HSC Education Centers (Houses of Scientific Collaboration), from 12 to 18 years old, additional education on the basis of universities, free of charge, 30 centers. These organizations provide a broad base for finding talent and learning through projects. But this is not a search program for existing EEs. The benchmark is taken for the future, since teenage projects are funded. This is a resource of human capital for the future, and there is still no "factory" for the production of a new business. Since we are talking about teenagers, this is perhaps the only government decision that has a strategic long-term goal, which cannot be said about other decisions.

2. Centers at universities. The government finances 14 regional innovation centers at universities through a separate program. All of them have as a permanent members the large business corporations that have decided to participate in the project. Specific areas of research that will be funded have been indicated by the government. Regional governments are co-founders. These are static structures where relationships are predefined. Business buys R\&D from universities, government grants territory and expects tax revenue to rise. They were created to implement the idea of a triple helix, so that universities fulfill orders from large businesses and can exist without these orders only with funding from the state budget. Therefore, these centers are not copies of successful samples of self-organizing EEs from the top-7, in which there are no orders for the product, but there are rounds of investments in the formation and scaling of new businesses. But the organization of the centers in question is familiar to the participants. It is a continuation of the business culture of relations between universities and industry enterprises that has developed over the decades of socialism. The Triple Helix is familiar to industry universities and is therefore easily replicable.

Professors, as a rule, are used to teaching students and doing scientific research on behalf of organizations, but they are not used to starting their own business. The idea of a triple helix University - government - business Roshni Das proposes to supplement the augmented model has been referred to as the 'quadruple helix' model. A fourth spiral is softer aspects of innovation, such as institutional norms, procedures and conventions. (Roshni, 2021) But this addition does not help, since changing the prevailing informal rules between the branches of the spiral, for example, between universities and the government, requires a significant change in political culture in favor of granting autonomy to universities from the government and life-long hiring of professors for their independence from the administration. Organizational and cultural dynamics and motivation in academia differs significantly from commercial laboratories. (Roshni, 2021) It assumes an arm's length relationship with business. (Alpatov and Anokhina, 2021) The scientific community is an institution that society trusts because of the integrity of scientists. The introduction of market incentives into the academic environment deprives society of this source of honest and objective expertise. 
Therefore, creating new EEs at universities means coming into conflict with the informal institutions that have developed between the participants in the spiral. As the rankings (Startup Genome, 2021) show, the top-7 EEs do not belong to universities or specific laboratories. These are regional associations of many participants. Universities are needed by founders and investors to rent scientific laboratories, not as owners of EEs. Regional EEs should not be locked into a specific legal entity. But this should be the place where people apply for support of their projects and receive an assessment of the possibility, funding and protection of property rights, regardless of which country they are resident in. EEs by their functional nature are a global institution, since there are few promising projects and countries are forced to compete for both projects and the human capital of founders. The smaller the country, the fewer creative people, and the more open to foreign participants the local EEs will be.

While the mature EEs submits to the rules it has created for each new entrant, the developing EEs, as an imprint of a foreign model, turns out to be in contradiction with the cultural traditions of the country. In Russia, the previous model of business culture emphasized a hierarchical, centralized structure for managing science. It is very difficult to get away from the administrative relations of organizing the scientific process, when researchers have bosses who form a pyramid of administrative subordination, and all scientists are hired, when proactive exploratory research must be included in the R\&D plan for government funding. This order of approval from the administration contrasts with the proactive behavior of individuals in EEs, both founders and venture capitalists.

3. EEs Moscow - Center for the Development and Commercialization of New Technologies "Skolkovo" ("Skolkovo").

Sometimes it seems easier to create a new business model than to try to transform the old one. A breakthrough business model will destroy the former informal institutions and business models (Smirnov et al., 2021). EEs Skolkovo was created in Russia precisely as a breakthrough organizational technology. On an undeveloped plot of land near Moscow, buildings were erected and people who worked abroad were invited. The imprint of the Silicon Valley was supposed. But the cultural factor and, above all, the factor of political culture played a role, which was reflected in the inhibition of the formation of private venture capital. There is nothing comparable to the leading EEs in terms of Exits.

EEs Moscow is one of the eight that have raised more than $\$ 4$ billion over the past 10 years (Startup Genome, 2021) Ecosystems with 4 or More in \$ B Club in Last 10 Years. But it is not included in the Top Ecosystems with Total Early-Stage Funding. Weak support at an early stage, where the risk of failure is high, usually indicates a shortage of promising projects, as a result of which there is no basic condition for venture capital. Typically, for a venture investor to work effectively, his portfolio should have from 30 to 50 startups. Risk aversion is characteristic of public investor behavior.

However, the rating data shows for EEs Moscow that Funding and Talant indicators are 10 out of 10 . According to the Performance indicator - only 6 out of 10 , which means the absence of exits with high profitability, which is confirmed by the weak market coverage indicator of 1 point out of 10 . Therefore, there is not a lack of venture capital, but a lack of start-ups, followed by an underdevelopment of private venture capital.

It is quite easy to financially create venture funds, for example, creating a Russian venture capital company RVC as a state investor. But the main problem is the problem of the project portfolio. When there is a shortage of them, garbage projects are financed, since in accordance with the conditions of the cultural environment, the state budget money must be invested. In order for the generators of ideas for the won grants to produce not scientific articles, but to create startups, funding of the early stages is necessary. But this contradicts the responsibility of officials for spending and returning public funds. It is safer for them to fund projects with proven cost-effectiveness. 
The emergence of the first breakthrough innovations is important in the transition to a new organization of entrepreneurship. Due to their high profitability, they are able to create a demonstration effect for followers of investors (Sipola, 2020), in which the action of the self-organization mechanism of EEs is manifested. You can build a collaboration of organizations and call it EEs. However, without voluntary networking of numerous founders and investors, without self-organization into a system, there will be no demonstration effect. Founders with disruptive technology ideas will prefer EEs with a friendly environment. As a consequence, as the Skolkovo example confirms, the existing business culture also leads to the avoidance of such EEs by people with promising business ideas and the underdevelopment of private venture capital. The underdevelopment of venture capital is a consequence of the lack of promising startups, and their shortage is not a consequence of the lack of people with such projects, but a consequence of their preference for other EE, which is facilitated by globalization.

\section{Discussions}

Analyzing the differences in rankings, it is not difficult to see that many ecosystems do not have their own knowledge base. The reason for their success is in value creation and exits, in well-established action algorithms. So, most unicorns, that is, private companies with reported valuations above $\$ 1$ billion, gave recent investors major protections such as initial public offering (IPO) return guarantees (15\%), vetoes over down-IPOs $(24 \%)$, or seniority to all other investors $(30 \%)$. These measures allow them to inflate their market value. (Gornall and Strebulaev, 2019) The presence of the entire set of EE resources does not yet indicate an advantage, do not yet make it a system. Resource approach does not include procedures for attracting talent from all over the world, who are met by established funding elements, regulators and organizational culture that improve the Performance indicator. Despite the lack of knowledge production, a number of EE still end up in the top 30 thanks to friendly environments and successful exits. Consequently, here we see the lack of a resource-based approach to create competitive advantages. The use of the resource-based view remains limited relative to institutional theory. (Beamish and Chakravarty, 2021) The resource approach should focusing on behaviors, without which the phenomenon of path dependence is not clear. (Greve, 2021)

The participation of the state in the process of forming EE is necessary, because independently owned startups typically lack resources, are constrained in their access to key resource providers. (Zahra, 2021) As industries move closer to the technological frontier in more knowledge-intensive sectors, they require different institutions, support, and policy support. (Anand et al., 2021) Relations with the state are relations within the framework of the prevailing political culture. The weaknesses of the state are manifested in these relations. Just as acquisitions produce large changes in provider behavior and outcomes, the same adjustment effect accompanies relationships in EE when the creator of EE is the state itself.

Deficiencies in political culture including corruption and uncertainty determine the quality of EE. The negative effect of corruption on investment in domestic firms is driven by corruption uncertainty rather than corruption level. (Hanouseke et al., 2021) However, there is a positive relationship between corruption and the likelihood of leaving the market. (Sartor and Beamish, 2020) State intervention through mandates in itself instead of the goal of general coherence of organizational action increases uncertainty. (Xie et al., 2021) When the state assumes the role of an investor, the uncertainty of the timing of financing of already started innovative projects is added.

In the process of the formation of the EE, a new business culture emerges. From the perspective of a resource-based view, the community itself in which a firm is embedded is 
inimitable, and nonsubstitutable resource that holds potential as a source of sustained competitive advantage. (Gibson et al., 2021) In EE not only new business is created, but also new experience as a result of on-the-job training. The team that failed the project is preferable to the team of newcomers. They have experience of failure and experience of creation. At the same time, obsolescence lowers the return to experience. (Deming and Noray, 2020) Domestic venture capital firms are more likely to invest in early stage ventures and high-tech industries after gaining experience. They learn from their foreign $\mathrm{VC}$ partners, and knowledge and skills give them confidence and improve their subsequent investment decisions. (Khurshed et al., 2020)

The pressure of political culture on the emerging relations between participants of EE in the long term is weakening, thanks to a change in political culture towards the complementarity of public and private investments and less regulatory interference. The state, initiating the creation of EE, seeks to establish EE on its territory. National interests are in conflict with the global nature of EE. Therefore, the state finds itself in competition with the governments of other countries for creating a friendly institutional environment for startups and private venture funds.

The case of a friendly political culture is the activities of the Austrian government agency. Austrian Business Agency (ABA) report directly to the Federal Ministry for Digital and Economic Affairs and have staff of around 32 employees in Vienna. In 2020, ABA provided professional consulting services to 353 international companies setting up business operations in Austria, accounting for a total investment volume of EUR 580.2 million. 2.165 new jobs were created as a result of these investments. On balance, ABA has concluded projects attracting total investments of EUR 12.2 billion, creating 67.659 jobs, since its founding in the year 1982. (ABA - Invest in Austria, 2021)

In order to invite investors, $\mathrm{ABA}$ has created the following advantages for them in Austria: a flexible stock market facilitates attractive deals with Austrian and European startups; high political stability and a reliable legal system provide a business-friendly environment; access to more than 600,000 startups in Europe. There is a friendly tax system in Austria: corporate tax 25\%; tax premium for R\&D 14\%; no value added tax; availability of double taxation treaties. The state maintains a global incubator network which provides full package services including coverage of flights and accommodation, co-working space, access to events \& pitching sessions. (GIN, 2021)

\section{Conclusion}

The following main results were obtained:

- Despite repeated market reforms, the quality of Russian EEs does not match the level of the country's economic development. The explanation can be found in the field of statism politics, which has survived from the Soviet past.

- A mature EEs forces every new member of the community to accept its rules, and an evolving EEs obeys the code of behavior that existed before it appeared.

- As a result of the contradiction that has arisen between the cultural environment and the need for security and support for startups, there is an outflow of startups to EEs with a friendly environment. This is the main reason for the lack of private venture capital in the country. The government is forced to compensate for the lack of private investors with public investments in relatively less profitable startups. Thus, the quality of the cultural environment takes the first place in the development of measures for the growth of private venture capital and, accordingly, the effectiveness of the entire innovation process in the country. 


\section{References}

1. ABA - Invest in Austria (2021). About us. https://investinaustria.at/en/about-aba/.

2. Alpatov, G., Gusarov, K., \& Korostyshevskaya, E. (2020). Impact of the funding structure on R\&D in cases of European Union and Russian Federation. Proceedings of the 20th international scientific conference Globalization and its socio-economic consequences. University of Zilina, Slovak Republic.

3. Alvedalen, J., \& Boschma, R. (2017). A critical review of entrepreneurial ecosystems research: towards a future research agenda. European Planning Studies, 25(6), 887.

4. Anand, J., McDermott, G., Mudambi, R., \& Narula, R. (2021). Innovation in and from emerging economies: New insights and lessons for international business research. Journal of International Business Studies, 52, 545-559.

5. Avnimelech, G., Teubal, M. (2006). Creating venture capital industries that co-evolve with high tech: insights from an extended industry life cycle perspective of the Israeli experience. Research Policy, 35(10), 1477-1498.

6. Beamish, P.W., \& Chakravarty, D. (2021). Using the resource-based view in multinational enterprise research. Journal of Management, 47(7), 1861-1877.

7. Deming, D.J., \& Noray, K. (2020). earnings dynamics, changing job skills, and stem careers. The Quarterly Journal of Economics, 135(4), 1965-2005.

8. Gibson, C.B., Gibson, S.C., \& Webster, Q. (2021). Expanding our resources: Including community in the resource-based view of the firm. Journal of Management, 47(7), 1878-1898.

9. GIN (2021). Benefits of go Austria. https://www.gin-austria.com/programs/goAustria.

10. Gokhberg, L. M., Gracheva, G. A., \& Ditkovsky, K. A. (2021). Indicators of innovative activity: 2021: statistical collection. University Higher School of Economics.

11. Gornall, W., \& Strebulaev, I. A. (2019). Squaring venture capital valuations with reality. Journal of Financial Economics (JFE), 2.

12. Greve, H.R. (2021). The resource-based view and learning theory: Overlaps, differences, and a shared future. Journal of Mamagement, 47(7), 1720-1733.

13. Guriev, S., Melnikov,N., \& Zhuravskaya, E. (2021). 3G internet and confidence in government. The Quarterly Journal of Economics, 136(4), 2533-2613.

14. Khurshed, A., Mohamed, A., Schwienbacher, A., \& Wang, F. (2020). Do venture capital firms benefit from international syndicates? Journal of International Business Studies, 51, 986-1007.

15. Hanousek, J., Shamshur, A., Svejnar, J., \& Tresl, J. (2021). Corruption level and uncertainty, FDI and domestic investment. Journal of International Business Studies.

16. Roshni, D. (2021). Cultural determinants of national innovativeness: A 56 country Bayesian analysis. Technology Analysis \& Strategic Management.

17. Sakari S., (2021). Another Silicon Valley? Tracking the role of entrepreneurship culture in start-up and venture capital co-evolution in Finland's entrepreneurial ecosystem 1980-1997. Journal of Entrepreneurship in Emerging Economies, 20534604.

18. Sartor, M.A., \& Beamish, P.W. (2020). Integration-oriented strategies, host market corruption and the likelihood of foreign subsidiary exit from emerging markets. Journal of International Business Studies, 51, 414-431. 
19. Smirnov, S.A., Bobrova, S.V., Arenkov, I.A., \& Salihova, J. Y. (2021). Sustainable combinations of distinctive features of innovative firms' business models. St Petersburg University Journal of Economic Studies, 37(1), 62-83.

20. Startup Genome. (2021). The Top Global Ecosystems of Today and Tomorrow. https://startupgenome.com/article/rankings-top-40.

21. Startup Genome (2020). Rankings 2020: Top 100 Emerging Ecosystems https://startupgenome.com/article/rankings-top-100-emerging.

22. UNESCO. (2020). Science, technology and innovation. Institute for Statistics. http: //data.uis .unesco.org / Index.aspx? DataSetCode $=$ SCN_DS \& lang = en.

23. World Bank. (2021). Ease of Doing Business rankings https://www.doingbusiness.org/en/rankings

24. Xie, X., Shen,W., \& Zajac, E.J. (2021) When is a governmental mandate not a mandate? Predicting organizational compliance under semicoercive conditions. Journal of mamagement, 47(8), 2169-2197.

25. Zahra, S.A. (2021). The resource-based view, resourcefulness, and resource management in startup firms: A proposed research agenda. Journal of Management, 47(7), 1841-1860. 